\title{
Influência da variabilidade climática na dinâmica da vegetação natural do bioma Mata Atlântica - abordagem multitemporal
}

A variabilidade do clima é um fator essencial para as florestas tropicais. A precipitação e temperatura são variáveis climáticas que influenciam no padrão espacia e temporal da vegetação e essa interação clima-vegetação influencia o clima regional a partir do mecanismo de feedback dos fluxos de energia, água e momento, o que pode afetar os serviços ecossistêmicos. Este estudo tem como objetivo analisar como o padrão anual das variáveis climáticas influencia a sazonalidade da vegetação na porção Paulista da região da bacia hidrográfica do rio Paraíba do Sul, cuja área apresenta importância ecológica por abrigar remanescentes de vegetação natural florestais do bioma Mata Atlântica. Usamos séries temporais de índices de vegetação como EVI e LSWI do sensor MODIS para mostrar as relações temporais. Os resultados mostram a utilidade das séries temporais dos índices na caracterização da dinâmica fenológica, tornando possível identificar os padrões de maior produtividade no período da estação chuvosa, época em que a condição hídrica é mais intensa, favorecendo o verdejamento das folhas, e quando há o déficit hídrico, que ocorre principalmente na estação seca, ocorre o declínio dos valores dos índices.

Palavras-chave: Variabilidade Climática; Séries Temporais; Índices de Vegetação; Mata Atlântica.

\section{Influence of climate variability on the natural vegetation dynamics of the Atlantic Forest biome - multitemporal approach}

Climate variability is an essential factor for tropical forests. Precipitation and temperature are climatic variables that influence the spatial and temporal pattern of vegetation and this climate-vegetation interaction influences the regional climate from the feedback mechanism of energy flows, water and momentum, which can affect the ecosystem services. The objective of this study is to analyze how the annual pattern of climatic variables influences the seasonality of the vegetation in the São Paulo region of the watershed of river Paraiba do Sul, whose area is ecologically important for housing remnants of forest natural vegetation of the Atlantic rainforest Biome. We use temporal series of vegetation indices such as EVI and LSWI of the MODIS sensor to show temporal relationships. The results show the usefulness of the time series of indices in the phenological features, making it possible to identify the higher productivity patterns in the period of the rainy season, when the water condition is more intense, By favoring the verdejamento of the leaves, and when there is the water deficit, which occurs mainly in the dry season, occurs the decline of the values of the indices.

Keywords: Climate Variability; Tropical Forests; Climate-Vegetation Interaction; Vegetation Índices.

Topic: Tecnologia, Modelagem e Geoprocessamento

Reviewed anonymously in the process of blind peer.
Received: $10 / 04 / 2018$

Approved: 24/05/2018
Suzana Inacio Carvalho

Universidade Estadual Paulista, Brasil

http://lattes.cnpq.br/1165756916766471

suzana-carvalho@live.com

Jonas Teixeira Nery

Universidade Estadual Paulista, Brasil

http://lattes.cnpq.br/1144640966519835

http://orcid.org/0000-0003-0577-8228

jonas@ourinhos.unesp.br
Referencing this:

CARVALHO, S. I.; NERY, J.. Influência da variabilidade climática na dinâmica da vegetação natural do bioma Mata Atlântica - abordagem multitemporal. Revista Ibero Americana de Ciências Ambientais, v.9, n.4, p.351-361, 2018. DOI: http://doi.org/10.6008/CBPC2179$\underline{6858.2018 .004 .0028}$ 


\section{INTRODUÇÃO}

Em regiões tropicais, como a Mata Atlântica, a sazonalidade climática, especialmente da precipitação, influencia a sazonalidade da vegetação. Nimer (1979) considera que nenhum fenômeno da natureza pode ser avaliado isoladamente e que a vegetação, por exemplo, não pode ser compreendida nem explicada se não for considerado o meio atmosférico no qual se insere, ou seja, o clima dominante. Estudos corroboram que a resposta de diferentes tipos de vegetação é modulada pela variação climática (BATISTA et al., 1997; BARBOSA, 1998; WANG et al., 2003). A variabilidade climática interanual deve propiciar variabilidade interanual na dinâmica da vegetação. Assim, durante a avaliação das variabilidades climáticas e vegetacionais em um determinado período, observa-se a ocorrência de ciclos de maior ou menor produtividade primária, o que denota em ciclos com maior ou menor absorção e fixação de carbono atmosférico, influenciando diretamente no clima regional. Segundo Prentice et al. (1992), mudanças na vegetação implicam em alterações das propriedades físicas da superfície, incluindo o índice de área foliar, a profundidade das raízes, a disponibilidade de umidade do solo, o albedo superficial e a rugosidade da superfície.

Assim, a realização do monitoramento preciso da variabilidade interanual e as tendências de longo prazo na estrutura dos ecossistemas tem se tornado muito importante, pois permite indicações essenciais de mudanças na biosfera terrestre que, do contrário, passariam despercebidas até o início de uma mudança de estado de equilíbrio do ecossistema.

Uma área de grande interesse, ainda pouco investigada, é a Mata Atlântica Paulista, inserida na bacia hidrográfica do rio Paraíba do Sul, cujo bioma original Mata Atlântica, tem sido substituído por pastagens, cultivos agrícolas como também práticas silviculturais. Nesta região, a Mata Atlântica mantém aproximadamente 30,5 \% da sua vegetação original, localizada na subdivisão da Serra da Mantiqueira e Serra do Mar. Este bioma apresenta peculiaridades quanto ao funcionamento ecofisiológico imposta pela variação do clima regional, bem como relacionadas às variações na latitude, longitude e altitude.

A atual situação em que a Mata Atlântica se encontra, em que cada vez mais áreas são fragmentadas, havendo uma constante perda de informações sobre a dinâmica do seu sistema natural, a utilização de técnicas de sensoriamento remoto tem proporcionado uma alternativa promissora para aprimorar a compreensão da dinâmica da vegetação e sua relação com fatores climáticos. Poucos estudos abordam a influência da variabilidade climática na vegetação natural desta região. $O$ presente estudo tem como objetivo identificar as relações entre o comportamento temporal dos índices de vegetação e a variabilidade das variáveis climáticas como precipitação pluvial e temperatura em áreas de vegetação florestal nativa da Mata Atlântica Paulista.

\section{METODOLOGIA}

\section{Área de estudo}


A bacia hidrográfica do rio Paraíba do Sul compreende a uma área de $55.500 \mathrm{Km}^{2}$ e está localizada na região hidrográfica do Atlântico Sudeste, entre as latitudes 2026' e 23000' e longitudes 4100' e 4630 (Figura 1). Exibe uma forma alongada, limitada ao Norte pelas bacias dos rios Grande e Doce e pelas serras da Mantiqueira, Caparaó e Santo Eduardo; a Nordeste pela bacia do rio Itabapoana; ao Sul, pela Serra dos Órgãos e pelos trechos paulista e fluminense da Serra do Mar, e a Oeste, pela bacia do rio Tietê, da qual é separada por meio de diversas ramificações dos maciços da Serra do Mar e da Serra da Mantiqueira (AGEVAP, 2015). Está situada numa região de relevo muito acidentado, atingindo mais de $2.000 \mathrm{~m}$, com destaque para o Pico das Agulhas Negras com 2.787 m de altitude, situado no Maciço do Itatiaia. Mas é na porção Paulista que ocorre um dos maiores remanescentes do bioma Mata Alântica do Brasil, apresentando uma grande importância ecológica

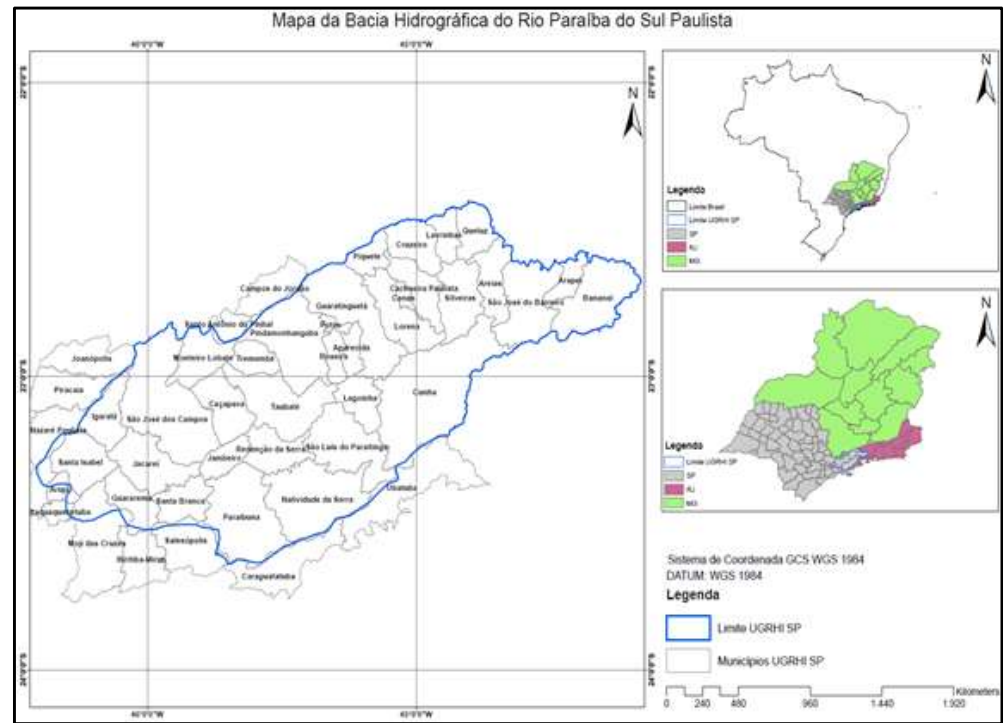

Figura 1: Mapa de localização da região da bacia hidrográfica do rio Paraíba do Sul Paulista.

Para analisar o comportamento temporal da vegetação natural da Mata Atlântica Paulista foram definidas três unidades amostrais na região de estudo. Para a definição das unidades amostrais, foi estabelecida uma área de 10 x $10 \mathrm{Km}$, obedecendo o critério de estarem contidas em áreas preservadas, onde houvesse o mínimo de intervenção (Figura 2). Neste sentido, dados referente a Áreas de Preservação Ambiental (APA) e Unidades de Conservação (UCS) foram adquiridos, uma vez que são áreas geográficas destinadas à preservação dos ecossistemas naturais e que possuem limites definidos e existem sob um regime especial de administração, a qual se aplicam garantias adequadas de proteção. Foram verificadas na região da UGRHI as Ucs onde foi possível identificar as melhores áreas para delimitação das áreas amostrais. Neste trabalho, foram selecionadas unidades de extrema importância ecológica, como A1 (Parque Nacional Serra da Bocaina) que está situado dentro dos domínios florísticos da Zona Neotropical e agrupa diversidade de formações vegetais, A2 (Parque Estadual Serra do Mar) sendo considerado o maior corredor biológico da Mata Atlâtnica, um dos maiores remanescentes de Floresta Ombrófila Densa e A3 (Área de Proteção Ambiental Serra da Mantiqueira) que também agrupa diverisidade de formações vegetais característicos da Mata Atlântica. 


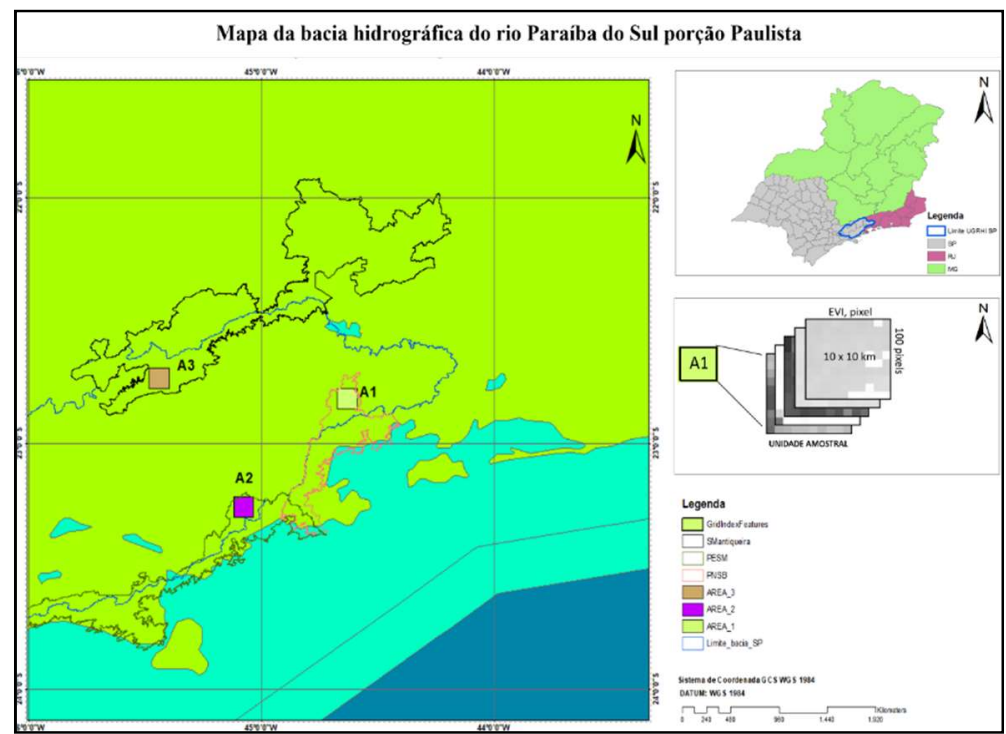

Figura 2: Delimitação de unidades amostrais para análises comparativas entre índices de vegetação e variáveis climáticas.

\section{Medidas físicas}

Foi utilizado um banco de dados para uma série temporal de 2000 a 2010 contendo os produtos MOD13Q1, que é responsável por disponibilizar dados de EVI (Equação 1), incluindo as bandas utilizadas para a geração deste índice: azul, vermelho, infravermelho próximo, além de uma banda localizada na faixa do infravermelho médio (banda 7), a cada 16 dias, totalizando 23 imagens por ano e resolução espacial de $1 \mathrm{Km}$. Esta etapa requer o cadastro e acesso no site <https://reverb.echo.nasa.gov/reverb/>, onde é realizado o pedido e aquisição dos produtos. Após a confirmação dos pedidos via e-mail, a NASA envia o link em que os produtos serão baixados. As imagens brutas apresentam projeção Integerized Sinusoidal (formato HDF Hierarquical Data Format) e o passo subsequente é a conversão das imagens no Modis Reprojection Tool (MRT), para a projeção geográfica e formato Geotiff e, em seguida, as imagens são importadas para o software ENVI. O índice LSWI foi obtido através do algorítmo que é a combinação linear de bandas do infravermelho próximo e médio que são obtidas pelo produto MOD13Q1 (Equação 2).

$$
E V I=G \frac{\left(\rho_{m i r}-\rho_{\text {mid }}\right)}{\left(\rho_{n i r}+C_{1} \rho_{\text {red }}+C_{2} \rho_{\text {blue }}+L\right)}(1+L)
$$

Onde, L é o fator de ajuste para o solo, C1 e C2 são coeficientes de ajuste para efeito de aerossóis da atmosfera. Os valores dos coeficientes adotados pelo algoritmo do $E V I$ são: $L 1=1, C 1=6, C 2=7.5$ e o fator de ganho $G=2.5$ (HUETE et al., 1997; JUSTICE et al., 1998).

$$
L S W I=\frac{\left(\rho_{n i r}-\rho_{m i r}\right)}{\left(\rho_{m i}+\rho_{m i r}\right)}
$$

Onde $\rho$ representa o fator de reflectância nas bandas do infravermelho próximo (nir) e infravermelho médio (mir).

\section{Informações meteorológicas}

Para avaliar e compreender a variabilidade da precipitação e temperatura foi utilizado o limite da região da bacia hidrográfica do rio Paraíba do Sul Paulista como representado na Figura 1, e criado o banco 
de dados através de 31 séries meteorológicas da Agência Nacional das Águas (ANA), os dados foram obtidos através do site HIDROWEB para um período de 1976 a 2010 na região de estudo.

\section{Relações clima e vegetação}

A análise tem como parâmetro a escala vegetacional, ou seja, os dados de precipitação e temperatura são delimitados na mesma escala espacial e temporal dos índices biofísicos EVI, LSWI e LAI. Os dados climáticos foram interpolados para uma resolução espacial de $1 \mathrm{~km}$ e temporal de 16 dias, extraídos pelo programa openGraDS. Esta aplicação foi necessária para que os dados de clima fossem compatíveis com a escala das variáveis biofísicas (índices de vegetação). O diagrama representado na Figura 3 monstra as etapas para extração dos dados.

Esta fase consiste na caracterização estatística das séries temporais dos índices de vegetação no tempo e no espaço, bem como, as relações destes com as variáveis climáticas como a precipitação pluvial e temperatura. Diferentes programas foram utilizados, de acordo com a especificidade da análise, sendo: i) processamento no ENVI; ii) parte em linguagem de programação $R$, iii) estatísticas no software STATISTIC e iv) geração de layouts de mapas em ambiente OpenGrads, SURFER e ArcMap/ArcGis. As técnicas estatísticas utilizadas foram: i) Análise de variabilidade (nas séries de imagens de EVI, LSWI e LAI e em dados precipitação e temperatura): box plots, desvio padrão e z-score; ii) Análise de regressão linear (nas séries de imagens de EVI, LSWI e LAl e em dados precipitação e temperatura): cálculo de correlação, scatterplot.

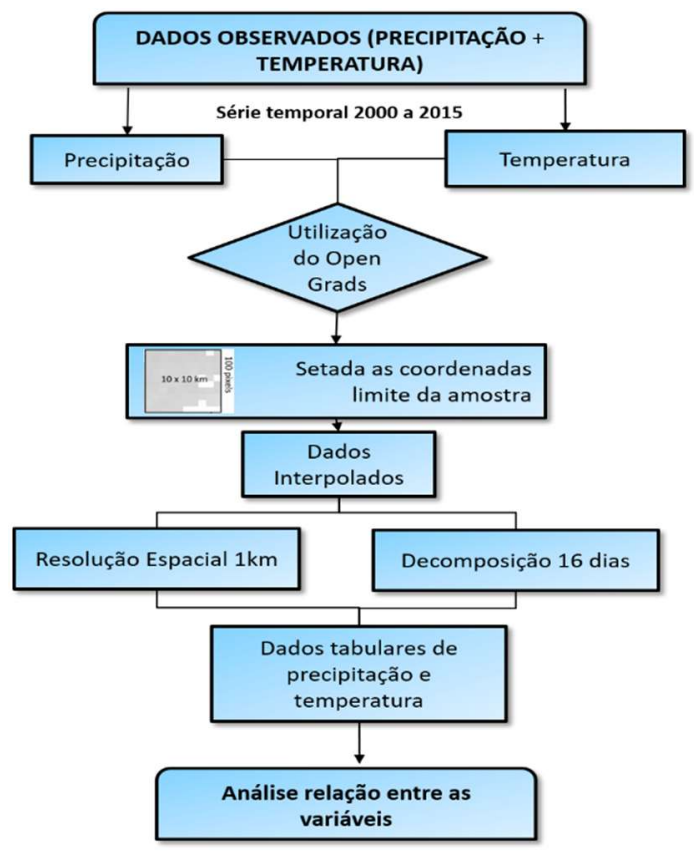

Figura 3: Metodologia para extração dos dados climáticos.

\section{RESULTADOS}

Através dos dados de precipitação pluvial, foi possível analisar a variabilidade temporal das séries meteorológicas para toda a região da bacia hidrográfica do rio Paraíba do Sul como mostra Tabela 1. 
Tabela 1: Cálculos estatísticos da precipitação pluviométrica (mm) para o período 1976-2010.

\begin{tabular}{|c|c|c|c|c|c|c|}
\hline Estação & Méd. & DP. & CV. & Máx. & Mín. & Ampl. \\
\hline 1 & 1308,23 & 317,86 & 0,24 & 1804,00 & 426,90 & 1377,10 \\
\hline 2 & 1253,62 & 271,40 & 0,22 & 1810,50 & 586,20 & 1224,30 \\
\hline 3 & 1699,01 & 432,63 & 0,25 & 2429,70 & 245,00 & 2184,70 \\
\hline 4 & 1562,13 & 271,82 & 0,17 & 2412,00 & 1108,10 & 1303,90 \\
\hline 5 & 2051,91 & 702,73 & 0,34 & 3408,80 & 1125,80 & 2283,00 \\
\hline 6 & 1340,27 & 248,45 & 0,19 & 1806,40 & 486,20 & 1320,20 \\
\hline 7 & 1231,07 & 249,78 & 0,20 & 1980,20 & 833,80 & 1146,40 \\
\hline 8 & 1663,23 & 292,69 & 0,18 & 2301,80 & 1048,70 & 1253,10 \\
\hline 9 & 1343,89 & 268,62 & 0,20 & 1804,00 & 426,90 & 1377,10 \\
\hline 10 & 1355,45 & 258,84 & 0,19 & 1946,30 & 829,70 & 1116,60 \\
\hline 11 & 1496,42 & 291,34 & 0,19 & 2085,20 & 788,30 & 1296,90 \\
\hline 12 & 1652,02 & 347,29 & 0,21 & 2503,90 & 1095,80 & 1408,10 \\
\hline 13 & 1807,96 & 317,54 & 0,18 & 2561,60 & 1253,60 & 1308,00 \\
\hline 14 & 1707,07 & 405,84 & 0,24 & 2677,70 & 793,40 & 1884,30 \\
\hline 15 & 1755,88 & 439,50 & 0,25 & 2734,10 & 971,60 & 1762,50 \\
\hline 16 & 1523,95 & 301,49 & 0,20 & 2380,80 & 951,20 & 1429,60 \\
\hline 17 & 1369,85 & 375,52 & 0,27 & 2410,50 & 648,50 & 1762,00 \\
\hline 18 & 1788,00 & 349,85 & 0,20 & 2832,00 & 1181,90 & 1650,10 \\
\hline 19 & 1696,17 & 290,47 & 0,17 & 2637,40 & 1010,80 & 1626,60 \\
\hline 20 & 1308,51 & 265,50 & 0,20 & 1891,00 & 821,70 & 1069,30 \\
\hline 21 & 1376,90 & 330,35 & 0,24 & 2196,30 & 518,20 & 1678,10 \\
\hline 22 & 1966,28 & 421,72 & 0,21 & 2970,30 & 921,00 & 2049,30 \\
\hline 23 & 1469,72 & 366,30 & 0,25 & 2464,10 & 683,30 & 1780,80 \\
\hline 24 & 1180,72 & 335,17 & 0,28 & 1968,80 & 374,90 & 1593,90 \\
\hline 25 & 1412,18 & 263,69 & 0,19 & 1955,50 & 876,50 & 1079,00 \\
\hline 26 & 1179,83 & 467,74 & 0,40 & 2007,70 & 101,10 & 1906,60 \\
\hline 27 & 1424,62 & 277,15 & 0,19 & 2210,10 & 786,30 & 1423,80 \\
\hline 28 & 1657,34 & 271,71 & 0,16 & 2521,40 & 1277,40 & 1244,00 \\
\hline 29 & 1463,08 & 332,64 & 0,23 & 2231,40 & 748,40 & 1483,00 \\
\hline 30 & 2333,14 & 616,30 & 0,26 & 3288,20 & 856,20 & 2432,00 \\
\hline 31 & 1457,57 & 393,71 & 0,27 & 2238,20 & 322,90 & 1915,30 \\
\hline
\end{tabular}

Legenda: Méd. - Média, DP - Desvio padrão, CV - Coeficiente de variação, Máx.- Máximo, Mín.- Mínimo, Amp - Amplitude.

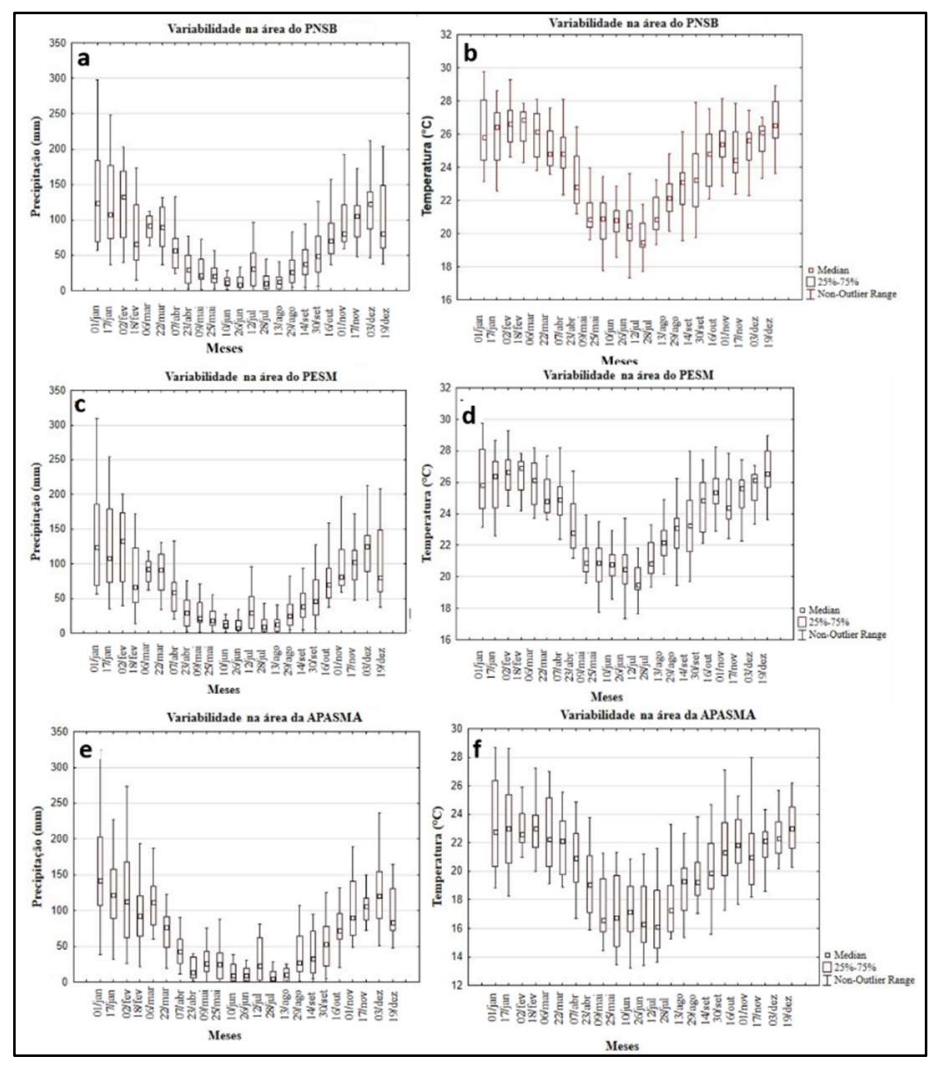

Figura 4: Variabilidade da precipitação pluvial e temperatura nas áreas PNSB, PESM e APASMA. 
Tabela 2: Estatística Correlação de Spearman.

\begin{tabular}{|l|l|l|l|l|l|l|}
\hline & $\begin{array}{l}\text { Prec. } \\
\text { PNSB }\end{array}$ & $\begin{array}{l}\text { Temp. } \\
\text { PNSB }\end{array}$ & $\begin{array}{l}\text { Prec. } \\
\text { PESM }\end{array}$ & $\begin{array}{l}\text { Temp. } \\
\text { PESM }\end{array}$ & $\begin{array}{l}\text { Prec. } \\
\text { APASMA }\end{array}$ \\
\hline Prec. PNSB & 1 & 0,89 & 1 & 0,89 & 0,98 \\
\hline Temp. PNSB & 0,89 & 1 & 0,89 & 1 & 0,86 & 0,90 \\
\hline Prec. PESM & 1 & 0,89 & 1 & 0,89 & 0,98 & 0,98 \\
\hline Temp. PESM & 0,89 & 1 & 0,89 & 1 & 0,90 & 0,86 \\
\hline Prec. APASMA & 0,98 & 0,86 & 0,98 & 0,86 & 1 & 0,88 \\
\hline Temp. APASMA & 0,90 & 0,98 & 0,90 & 0,98 & 0,88 \\
\hline
\end{tabular}

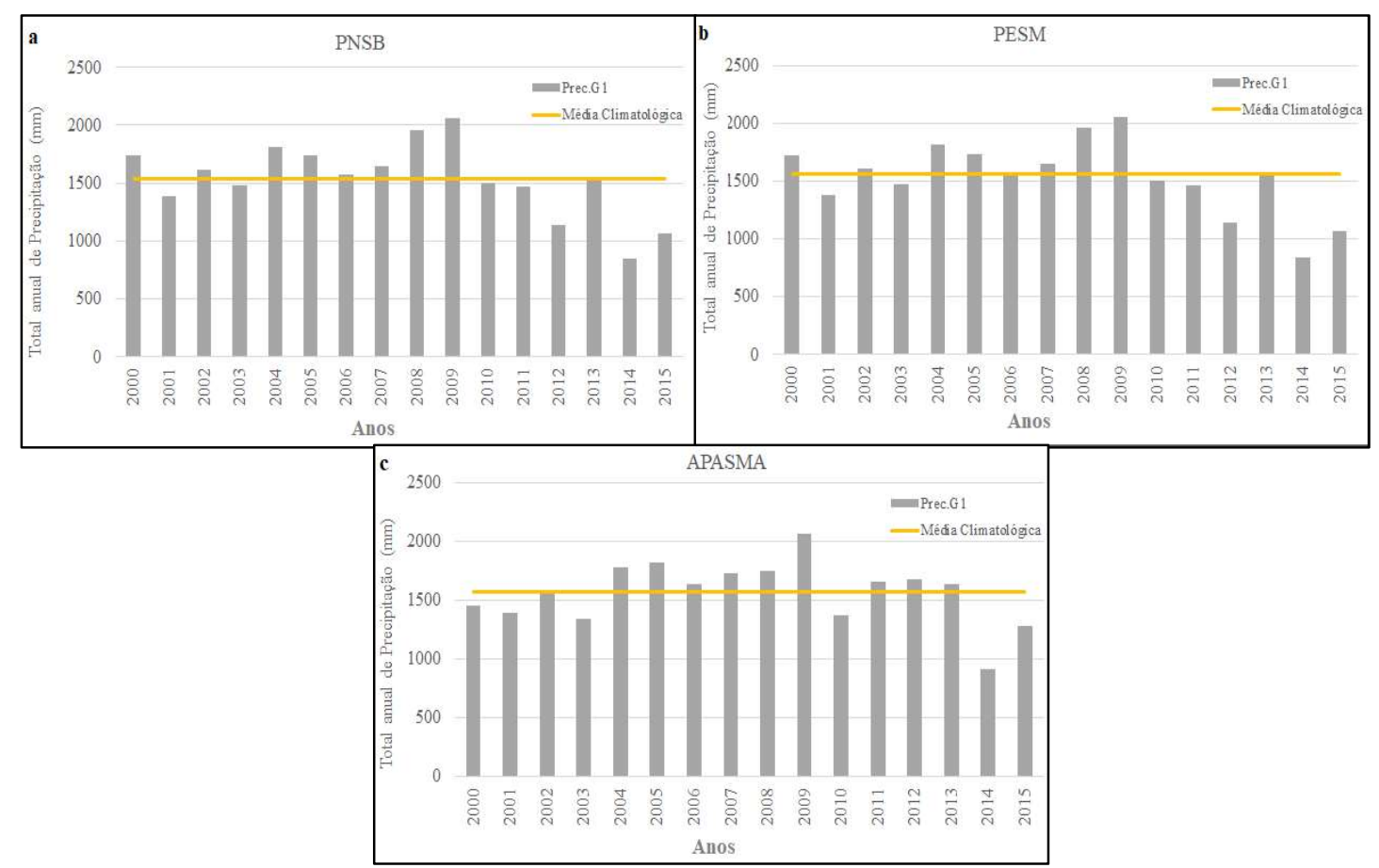

Figura 5: Variabilidade do total anual de precipitação e a média climatológica correspondente para as áreas PNSB, PESM, APASMA.

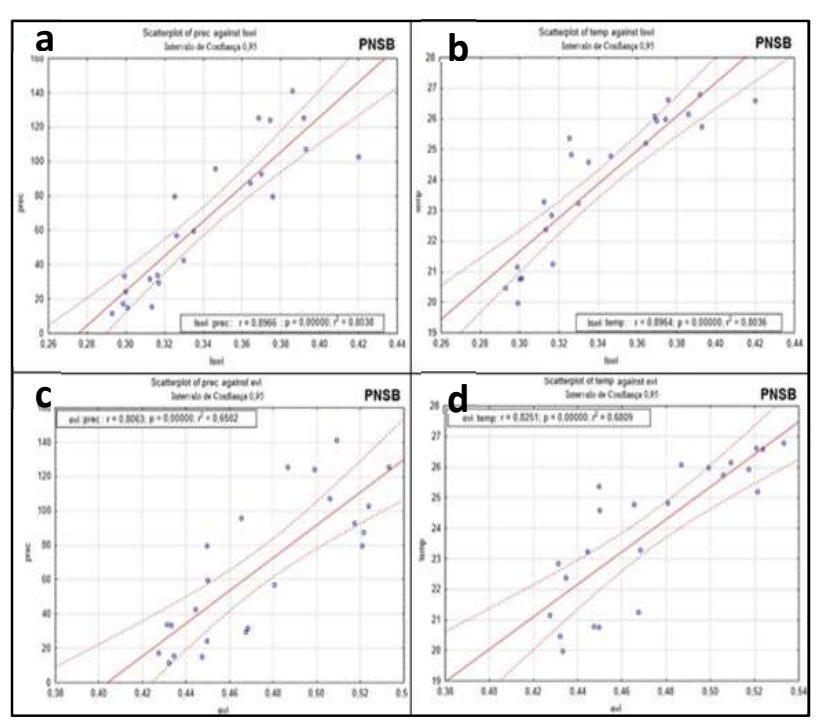

Figura 6: Scatterplot entre LSWI/EVI e as variáveis climáticas no PNSB.

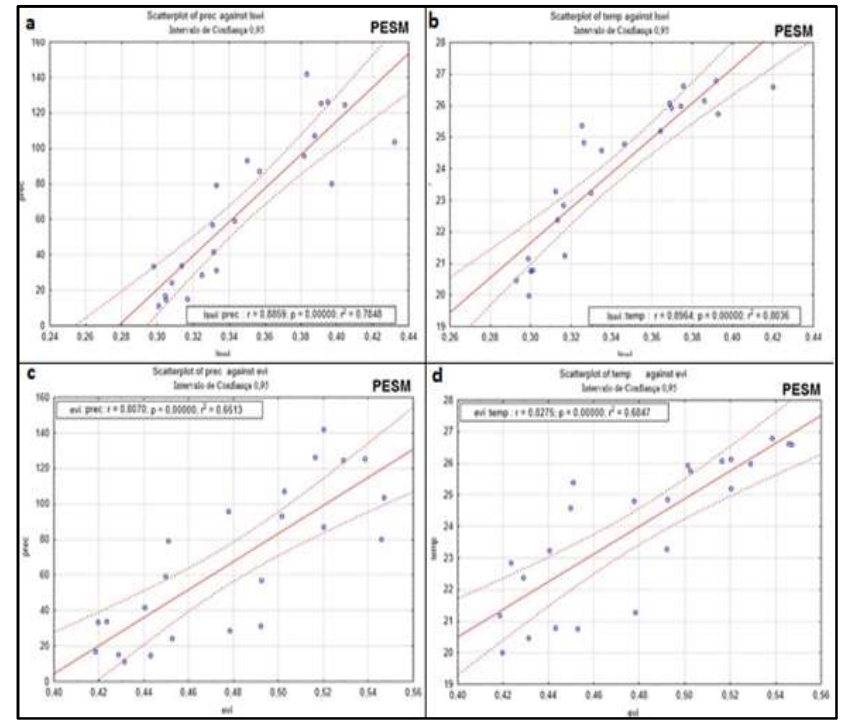

Figura 7: Scatterplot entre LSWI/EVI e as variáveis climáticas no PESM. 


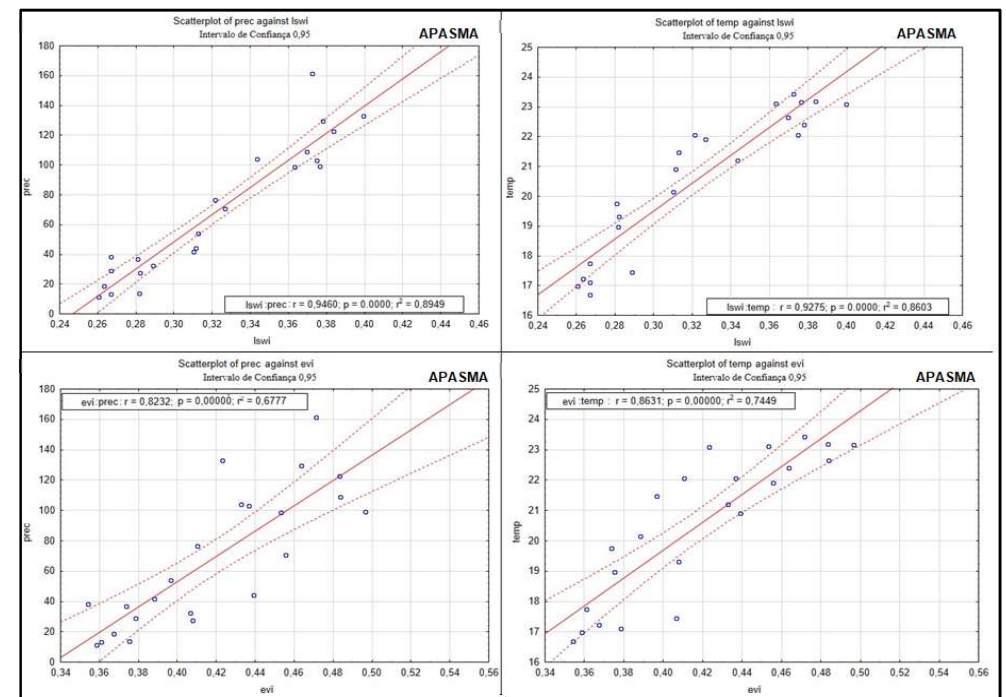

Figura 8: Scatterplot entre LSWI/EVI e as variáveis climáticas na APASMA.

\section{DISCUSSÃO}

A Tabela 1 mostra que das 31 séries meteorológicas 14 apresentam valores médios anuais acima de (1500 mm), caracterizando essa região com alto índice de umidade. Em geral, a maioria das séries apresentaram valores máximos acima de $2000 \mathrm{~mm}$ e uma maior variabilidade em relação aos valores mínimos. Em algumas séries como (Estações 3, 5, 25 e 33) a amplitude apresentou valor acima de 2000 mm, o que demonstra uma alta variabilidade de chuva nessas áreas.

A Figura 1 mostra através dos gráficos box plot a variabilidade dos dados de chuva e temperatura para a série de análise 2000 a 2015. De maneira geral é possível observar que o comportamento das variáveis nas três regiões de análise A1- Parque Nacional Serra da Bocaina (PNSB), A2 - Parque Estadual da Serra do Mar (PESM) e A3 - Área de Proteção da Serra da Mantiqueira (APASMA), seguem o padrão de chuvas mais intensas no verão e baixa precipitação no inverno (déficit hídrico).

Nesta etapa, é interessante identificar as possíveis diferenciações entre as regiões que englobam as áreas a fim de relacionar, posteriormente, com a dinâmica da produtividade, ou seja, em termos de biomassa da floresta natural da Mata Atlântica Paulista. O início da estação chuvosa, assim como sua intensidade e variabilidade espacial e temporal, são aspectos importantes do clima pois exerce uma importante função ecológica, como por exemplo nos padrões fenológicos da vegetação.

Os resultados mostram que a média da série utilizada de 2000 a 2015 indicam que o início da estação chuvosa ocorre entre os dias 14 de setembro no PNSB e PESM e em 16 de outubro na região da APASMA, enquanto que a estação seca ocorre entre os dias 25 de maio nas áreas PNSB e PESM e em 10 de junho na região da APASMA.

Nota-se temperaturas mais elevadas nos meses de verão (dezembro a março) e verifica-se a diminuição das temperaturas na transição entre as estações verão e inverno até ser observado as mínimas no período do inverno. Tal padrão, pode ser analisado através da correlação (Tabela 1), ou seja, nos meses onde há maior incidência de temperatura elevada se equipara ao período em que se encontra os valores 
maiores de chuva precipitada (verão) enquanto que no período oposto (inverno), as temperaturas são climatologicamente amenas e é onde encontra-se o período menos chuvoso do ano.

A Figura 2 mostra o total anual da precipitação sendo que os anos 2001, 2003, 2010, 2011, 2012, 2014 e 2015 apresentaram os totais anuais abaixo da média climatológica (1537,41 mm), com destaque para o ano de 2014 que apresentou anomalia negativa de 690,28 mm e em 2009, com valor de 525,96 mm de precipitação acima da média climatológica (Figura 2 a). É interessante observar o decréscimo de precipitação pluvial que se inicia ainda em 2013, com valores de precipitação abaixo da média no mês de dezembro (61, $29 \mathrm{~mm}$ ), constatando a irregularidade de chuva no verão, estação do ano que representa meses mais chuvosos. E o ano de 2014 se destaca por ter sido um ano em que a seca atingiu a região do Sudeste, devido a presença de bloqueios atmosféricos sucessivos, impossibilitando a chegada de chuvas o que proporcionou um evento extremo de seca na região.

Na região do PESM, a média anual da temperatura oscilou entre $24{ }^{\circ} \mathrm{C}$ a $29^{\circ}$. Também é possível observar o gradiente dos valores de temperatura, observando os valores máximos nos meses que compreende o verão e as mínimas no inverno. Assim como na área do PNSB os anos 2001, 2003, 2010, 2011, 2012, 2014 e 2015 apresentaram os totais anuais abaixo da média climatológica (1566,78 mm), com destaque para o ano de 2014 que apresentou anomalia negativa de 722,51 mm e em 2009, foi observado anomalia positiva, com valor de 525,96 mm acima da média climatológica (Figura 5 B).

Na região da APASMA, a média anual da temperatura oscilou entre $18{ }^{\circ} \mathrm{C}$ a $23{ }^{\circ} \mathrm{C}$, caracterizada por uma região com temperatura mais amena, no período da estação chuvosa poucos anos apresentaram temperatura máxima ultrapassando $23{ }^{\circ} \mathrm{C}$, como nos anos 2001 e em 2014, que no mês de janeiro apresentaram temperatura de $28^{\circ} \mathrm{C}$. Embora as temperaturas mantivessem valores mais amenos, o padrão observado nas áreas do PSNB e PESM, também foi observado, com as maiores temperaturas no período chuvoso (verão) e as mínimas na estação seca (inverno). É possível observar que em relação aos anos que apresentaram valores abaixo da média climatológica, além dos anos 2001, 2003, 2010, 2011, 2012, 2014, 2015 nessa região, o ano de 2000 também se enquadrou, apresentando anomalia negativa equivalente a 116, $70 \mathrm{~mm}$. Novamente é possível observar os padrões encontrados nos anos 2009 e 2014, sendo que em 2009 observa-se os valores máximos de precipitação, com 495,16 mm acima da média climatológica enquanto que para o ano de 2014 as anomalias negativas com 656,50 mm de precipitação abaixo da média climatológica (Figura 5 c).

Os resultados das relações de causa e efeito (as relações que se estabelecem) entre as variáveis climáticas e biofísicas da vegetação e que podem ser observados através dos diagramas de dispersão (scatter plot) como mostra as Figuras 6 a 8. A Figura 6 apresenta as relações encontradas na região do PNSB, indicando relações positivas e significativas entre o EVI e as variáveis precipitação e temperatura. Na Figura 6 a e b é possível observar a relação do LSWI indicando altas relações positivas e significativas entre os dados, com $r=0,89$ e $80 \%$ com a precipitação e $r=0,89$ e $80 \%$ de significância estatística com a temperatura. Para as relações do índice $E V I$ as Figuras c e d mostram valores de $r=0,80$ e $65 \%$ de significância estatística das relações do EVI com a precipitação e $r=0,82$ e $68 \%$ de significância estatística com a temperatura. A Figura 7 
apresenta as relações encontradas na região do PESM, e também revela relações positivas entre os índices EVI/LSWI com a precipitação e temperatura. Constatou-se que para o $65 \%$ da variação do EVI podem ser explicadas pela precipitação $(r=0,80)$ e $68 \%$ pela temperatura, enquanto que para $L S W I$ nota-se que a relação estabeleceu com $78 \%$ de significância para precipitação $(r=0,88)$ e $80 \%$ de significância para temperatura $(r=0,89)$. A Figura 8 apresenta as relações encontradas na região da APASMA e os resultados indicam que $67 \%$ da variação do EVI nessa região pode ser explicada pela variação da temperatura $(r=0,82)$ e que $74 \%$ de significância quanto a relação com a temperatura $(r=0,86)$. Para o LSWI (Figura 8 a e b), constatou-se que $89 \%$ da variação do índice deve-se a variação da precipitação $(r=0,94)$ e $86 \%$ explica-se pela temperatura $(r=0,92)$.

\section{CONCLUSÕES}

Considerando que a variabilidade climática tem grande influência na dinâmica sazonal da vegetação, o objetivo principal do presente trabalho foi tentar verificar esta condição através de variáveis climáticas e índices de vegetação na região da Mata Atlântica Paulista. Posto isto, nesse trabalho avaliou-se a variabilidade da precipitação para uma série histórica de 34 anos com o objetivo de compreender como a precipitação se comportou em escala de bacia hidrográfica. Todas as regiões (PNSB, PESM e APASMA) apresentaram variabilidade tanto nos dados de precipitação como nos dados de temperatura, apresentando padrão similar e relações positivas entre as variáveis climáticas. Destacaram-se os anos 2009 e 2014, sendo que o ano de 2009 representou um ano de anomalia positiva, com precipitação acima da média climatológica. Este fato pode estar relacionado ao evento La Niña, que ocorreu em 2008 e pode ter tido influência na distribuição das chuvas no ano 2009. Já em 2014, foi possível detectar uma condição de anomalia negativa, com condições mais severas com precipitação pluvial abaixo da média climatológica em toda região da bacia hidrográfica do rio Paraíba do Sul.

Trabalho realizado por Coelho et al. (2016) destaca que a seca sobre o Sudeste durante o verão de 2014 teve como raiz as condições de chuvas anômalas na região tropical ao norte da Austrália, desencadeando uma série de processos entre a região tropical e extratropical do oceano Pacífico, até atingir a região Sudeste do Brasil e oceano Atlântico adjacente. Com a finalidade de avaliar como essa dinâmica climática influencia na dinâmica da vegetação, os índices EVI, LSWI e LAI foram analisados. Os resultados dessa análise mostraram que o comportamento da dinâmica da vegetação natural das regiões da Mata Atlântica Paulista, verificadas nas áreas dos parques PNSB e PESM como na APA da Serra da Mantiqueira (APASMA), acompanha a varibilidade imposta pelo clima, em que foram observados os padrões de maior produtividade no período da estação chuvosa, época em que a condição hídrica é mais intensa, favorecendo o verdejamento das folhas, e quando há o déficit hídrico, que ocorre principalmente na estação seca, notase o declínio dos valores dos índices, ou seja, indicando a queda foliar.Embora os índices tenham capturado o padrão esperado, vale destacar que o índice LSWI apresentou maior sensibilidade à condição hídrica, sendo possível verificar o potencial das imagens do sensor MODIS em capturar a resposta da floresta e consequentemente contribuir de forma significativa para estudos de mudanças climáticas. 


\section{REFERÊNCIAS}

AGEVAP. Plano Integrado de recursos hídricos da bacia hidrográfica do rio Paraíba do sul e planos de ação de recursos hídricos das bacias afluentes: Relatório de diagnóstico. COHIDRO, 2014.

BARBOSA, H. A.. Análise espaço temporal de índice de vegetação AVHRR/NOAA e precipitação na região nordeste do Brasil, em 1982-85. Dissertação (Mestrado em Sensoriamento Remoto) - Instituto Nacional de Pesquisas Espaciais, São José dos Campos, 1998.

BATISTA, G. T.; SHIMABUKURO, Y. E.; LAWRENCE, W. T.. The long-term monitoring ofvegetation cover in the Amazonian forest region of northern Brazil using NOAAAVHRRdata. International Journal of Remote Sensing, v.18, n.15, p.31953210, 1997.

COELHO, C. A. S.; OLIVEIRA, C. P.; AMBRIZZI, T.; REBOITA, M. S.; CARPENEDO, C. B.; CAMPPS, J. L. P. S.; TOMAZIELLO, A. C. N.; PAMPUCH, L. A.; CUSTÓDIO, M. S.; DUTRA, L. M. M.; ROCHA, R. P.; REHBEIN, A.. The 2014 southeast Brazil austral summer drought: regional scale mechanisms and teleconnections. Climate Dynamics, v.46, n.11-12, p.37373752,2016

HUETE, A.; DIDANA, K.; MIURA, T.; RODRIGUEZ, P.; GAO, X.; FERREIRA, L. G.. Overview of the radiometric and biophysical performance of the MODIS vegetation indices. Remote Sensing of Environment, n.83, n.1-2, p.195-213, 2002.

JUSTICE, C. O.; VERMOTE, E.; TOWNSHEND, J. R. G.; DEFRIES, R.; ROY, D. P.; HALL, D. K.; SALOMONSON, V. V.; PRIVETTE, J. L.; RIGGS, G.; STRAHLER, A.; LUCHT, W.; MYNENI, R. B.; KNYAZIKHIN, Y.; RUNNING, S. W.; NEMANI, R.R.; WAN, Z.; HUETE, A. R.; VAN LEEUWEN, W.; WOLFE, R. E.; GIGLIO, L.; MULLER, J.; LEWIS, P.; BARNSLEY, M. J.. The Moderate Resolution Imaging Spectroradiometer (MODIS): land remote sensing for global change research. IEEE

Transactions on Geoscience and Remote Sensing, v.36, n.4, p.1228-1247,1998.

PRENTICE, I. C.; CRAMER, W.; HARRISON, S. P.; LEEMANS, R.; MONSERUD, R. A.; SOLOMON, A.. A global biome model based on plant physiology and dominance, soil properties and climate. Journal of Biogeography, v.19, n.2, p.117-134, 1992.

NIMER, E.. Climatologia do Brasil. Rio de Janeiro: IBGE, 1979.

WANG, J.; RICH, P. M.; PRICE, K. P.. Temporal responses of NDVI to precipitation andtemperature in the central Great Plains, USA. International Journal of Remote Sensing, v.24, n.11, p.2345-2364, 2003.

A CBPC - Companhia Brasileira de Produção Científica (CNPJ: 11.221.422/0001-03) detém os direitos materiais desta publicação. Os direitos referem-se à publicação do trabalho em qualquer parte do mundo, incluindo os direitos às renovações, expansões e disseminações da contribuicão, bem como outros direitos subsidiários. Todos os trabalhos publicados eletronicamente poderão posteriormente ser publicados em coletâneas impressas sob coordenação da Sustenere Publishing, da Companhia Brasileira de Produção Científica e seus parceiros autorizados. Os (as) autores (as) preservam os direitos autorais, mas não têm permissão para a publicação da contribuição em outro meio, impresso ou digital, em português ou em tradução. 